\title{
O DIABO COMO FORMA DE ESTABELECIMENTO DO DUPLO: UMA ANÁLISE DE “A IGREJA DO DIABO”, DE MACHADO DE ASSIS
}

\begin{abstract}
Resumo: O conto "A Igreja do Diabo", de Machado de Assis, foi publicado no livro "Histórias sem Data" (1884) e pode ser caracterizado por uma espécie de fábula, por carregar consigo elementos moralizantes que pretendem dar conta do que o indivíduo pode ou não realizar, das leis (divinas) que ele deve ou não seguir. O ensaio que aqui apresentamos pretende analisar o conto procurando explicitar a recorrência do duplo em todas as suas formas de manifestação. Para tanto se faz necessário, em primeiro lugar, tecer algumas considerações acerca do conto enquanto narrativa, da narrativa a ser analisada (o contexto literário em que ela se encontra) e da personagem do Diabo, mostrando o modo como ele se apresenta às pessoas e as metas que procura alcançar.

Palavras-chave: Narrativa. Duplo. Deus. Diabo.

Resumé: Le conte "A Igreja do Diabo", de Machado de Assis, a été publié dans le livre "Histórias sem Data" (1884) et peut être caracterisé comme un type de fable pour porter en soi quelques éléments moralisantes qui ont pour objectif régler ceux que l'individu peut ou ne peut pas réaliser, des lois divines qu' il doit ou non suivre. L'essai qu' on présentera a l'intention d'analyser le conte en essayant de découvrir la récurrence du double dans les plus diverses manières de manifestation. Pourtant, il faut, tout d'abord, considérer quelques aspects sur le conte comme un récit, du récit qu'on analyserai ( le cadre littéraire auquel il est inscrit) bien que du personnage du Diable, en montrant la façon pour lequel il se présente aux personnes et quels but qu'il veut rapporter.

Mots-clés: Récit. Le double. Dieu. Diable.
\end{abstract}

Introdução

Joaquim Maria Machado de Assis (Rio de Janeiro, 21 de junho de 1839 - Rio de Janeiro, 29 de setembro de 1908) foi um romancista, contista, poeta

\footnotetext{
* Professora de Língua Francesa no Instituto de Línguas da Ulbra (Universidade Luterana do Brasil) no campus de Canoas, RS. Graduada em Letras-Português/Francês pela Fundação Universidade do Rio Grande (FURG).Ensaio desenvolvido como requisito para o fechamento do curso $O$ duplo nos Contos de Machado de Assis, ministrado pelo professor João Ernesto Weber no Programa de Pós -Graduação em Letras, nível Mestrado, na Universidade Federal de Santa Catarina.
}

Uniletras, Ponta Grossa, v. 30, n. 1, p. 237-251, jan./jun. 2008 Disponível em <http://www.uepg.br/uniletras> 
e teatrólogo brasileiro. Considerado como um dos mais importantes nomes da literatura deste país, foi identificado, pelo crítico Harold Bloom, como o maior escritor afro-descendente de todos os tempos.

Sua vasta obra inclui também crítica literária. É considerado um dos criadores da crônica no país, além de ser importante tradutor, vertendo para o português obras como Os Trabalhadores do Mar, de Victor Hugo, e o poema O Corvo, de Edgar Allan Poe. Foi um dos fundadores da Academia Brasileira de Letras, também chamada de Casa de Machado de Assis, e seu primeiro presidente.

É considerado por muitos o maior escritor brasileiro de todos os tempos e um dos maiores escritores do mundo, enquanto romancista e contista. Suas crônicas não têm o mesmo brilho e seus poemas têm uma diferença curiosa com o restante de sua produção: enquanto na prosa Machado é contido e elegante, seus poemas são algumas vezes chocantes na crueza dos termos - similar, talvez, à de Augusto dos Anjos.

O crítico norte-americano Harold Bloom considera Machado de Assis um dos cem maiores gênios da literatura de todos os tempos (chegando ao ponto de considerá-lo o melhor escritor negro da literatura ocidental), ao lado de clássicos como Dante, Shakespeare e Cervantes. A obra de Machado de Assis vem sendo estudada por críticos de vários países do mundo e seu estilo literário tem inspirado muitos escritores brasileiros ao longo do tempo. Vale destacar que essa obra tem sido adaptada para a televisão, o teatro e o cinema. Em 1975, a Comissão Machado de Assis, instituída pelo Ministério da Educação e Cultura, organizou e publicou as edições críticas de obras de Machado de Assis, em 15 volumes. Suas principais obras foram traduzidas para diversos idiomas e grandes escritores contemporâneos, como Salman Rushdie, Cabrera Infante e Carlos Fuentes, confessam serem fãs de sua ficção, como também o confessou Woody Allen. A Academia Brasileira de Letras criou o Espaço Machado de Assis, com informações sobre a vida e a obra do escritor.

Machado em suas obras interpela o leitor, ultrapassando a chamada quarta parede. Nisso foi influenciado por Manuel Antonio de Almeida, que já havia utilizado a técnica, assim como Miguel de Cervantes e outros autores, mas nenhum deles a empregou com tanta ênfase quanto Machado. 


\section{Machado de Assis e o conto}

Nádia Gotlib (1985, p. 34), ao teorizar sobre o conto em seu livro Teoria do Conto diz: "O fato é que a elaboração do conto é produto de um extremo domínio do autor sobre os seus materiais narrativos. O conto, como toda obra literária, é produto de um trabalho consciente, que se faz por etapas, em função desta intenção: a conquista do efeito único ou impressão total. Tudo provém de minucioso cálculo". Com base nas idéias da referida autora, podemos afirmar que o conto é a forma narrativa, em prosa, de menor extensão (no sentido estrito de tamanho), ainda que contenha os mesmos componentes do romance. Entre as principais características do conto estão: a concisão, a precisão, a densidade e a unidade de efeito ou impressão total - da qual falavam Edgar Allan Poe (1809-1849) e Anton Tcheckov (1860-1904): o conto precisa causar um efeito singular no leitor; muita excitação e emotividade. No conto, o autor é capaz de realizar a plenitude de sua invenção, seja ela qual for.

Todavia, o conto, enquanto gênero literário, não foi uma categoria narrativa muito difundida; considerando o período inicial da literatura brasileira até o romantismo, poucos foram os escritores que se dedicaram a esse tipo de narrativa. Hoje, por outro lado, mesmo quem não faz parte de um meio acadêmico literário já estudou algum conto machadiano ou dele ouviu falar, visto que muitos dos contos de Machado são mais conhecidos que seus próprios romances. E isso pode ser confirmado a partir de uma afirmação de Fischer (1998, p. 147), que cita Meyer (1965), quando ele diz:

Bem sei que Machado conseguiu compor mais de um bom romance, mas, ainda sob a magia do melhor de seus romances, de vez em quando o leitor acorda, para sentir que ele é, sobretudo, um analista empenhado em extrair do "mínimo e escondido" a essência psicológica, o episódio mais importante para a continuidade do entrecho romanesco. Por isso mesmo, achou seu limite ideal de expressão no conto, em que só Tchekov pode emparelhar com ele.

Diante disso, é fundamental ressaltar que foi nos contos que o autor teve sua expressividade melhor legitimada. Em suas narrativas encontra-se perfeitamente um mundo inteiro que prescinde o mundo do romance; poderíamos até nos arriscar a dizer que seus contos são como prólogos de sua produção romanesca.

A narrativa machadiana tem no seu amadurecimento um processo 
constante e progressivo, visto que o autor trazia para a sua obra leituras de clássicos das literaturas inglesa, francesa, portuguesa, espanhola, alemã, russa e outras. Ele tinha um contato contínuo com a literatura universal, fato que explica a abundância de citações nas suas obras.

Felipe Matias, em sua análise intertextual entre Goethe, a partir de Fausto, e Machado, na Igreja do Diabo, toma emprestadas as idéias de José Guilherme Merquior no ensaio "Machado em perspectiva" e escreve a respeito das citações na narrativa machadiana: "Machado realmente cita com abundância, é o campeão das citações na literatura brasileira, e faz um uso muito especial dessas citações" (2007, p. 36). Em uma das citações inseridas no conto "A igreja do diabo", Machado faz alusão ao mito do Fausto: “- Não venho pelo vosso servo Fausto, respondeu o Diabo rindo, mas por todos os Faustos do século e dos séculos" (MATIAS, 2007, p.370). Nesse conto, Machado de Assis constrói o segundo capítulo de acordo com a cena "Prólogo no céu"- da obra Fausto, produzida pelo alemão Goethe.

Portanto, podemos afirmar que Machado de Assis é singular na Literatura Brasileira. Ele adaptou a clássica língua portuguesa para tratar dos assuntos pertinentes aos interesses do brasileiro "atemporal", ou seja, do homem universal. A literatura machadiana surge, nesse sentido, para expressar uma realidade nova da qual a língua sentia necessidade. Não se envolvendo em questões políticas, seus romances e, principalmente, seus contos traziam problemas ligados à psique humana, às formas de destrinchar os problemas referentes à alma humana. Seu primeiro trabalho como contista, o livro "Contos Fluminenses", assim como "Histórias da Meia-Noite", o segundo, trazem a temática "romântica" da questão da ascensão social a qualquer custo. Esse tema já teria sido explorado em "A Mão e a Luva", "Iaiá Garcia", "Ressurreição" e "Helena"; quatro romances de uma fase que ainda trazia muito dos aspectos exercidos a esmo pelos escritores românticos. Alguns a chamam de fase de transição.

Há certo "didatismo" ao nos atrevermos a classificar o autor de "Dom Casmurro" desse modo, mas o fato percebido é que, a partir de "Papéis Avulsos", a situação muda significativamente, pois há nesse livro uma reunião de excelentes histórias a partir do grande aperfeiçoamento da linguagem. Existem, também, muitos aforismos, e nisso Machado é extraordinário. Logo a seguir, 
em "Histórias sem data", a qualidade dos seus contos continua a subir. Depois, segue-se a obra "Várias Histórias", com os brilhantes contos "A cartomante" e "Uns braços".

Bosi $\left(1978^{1}\right.$, p. 151) afirma que:

[...] há dois Machados, um anterior a Memórias Póstumas e a Papéis Avulsos, outro posterior; que a passagem de um para outro coincide com (se é que não se explica mesmo pela) ascensão social do cidadão Joaquim Maria; que a montagem das personagens corresponde a uma reflexão sobre a "máscara social", derivando daí uma galeria de tipos ocupados em interesses burgueses, seja para ascender socialmente, seja para escolher o parceiro de casamento, etc.; que os enredos e personagens manifestam alguma consciência que evolui segundo a mudança de percepção do autor [...].

Com base no trecho acima percebemos que, em seus contos, Machado de Assis faz um estudo dos pequenos problemas do ser humano. Através de apólogos, diálogos, aforismos, o autor tece uma teia de observação do ser humano e acaba analisando-o psicologicamente. Analisa as mais intrínsecas questões do indivíduo, mas a predominância do filosófico e do moralista é outro fato recorrente.

Segundo Fischer (1998), Machado seria um típico representante da filosofia pós -romântica para a qual é uma ilusão supor a autonomia do sujeito, ou ainda, pior que uma ilusão, um grave risco para o mesmo sujeito parecer diferente da média geral consentida. Disso teria surgido a qualidade principal dos contos-teorias, categoria da qual faz parte o conto a ser aqui analisado.

\section{A Igreja do Diabo}

O conto "A Igreja do Diabo", de Machado de Assis, foi publicado no livro "Historias sem Data" (1884) e pode ser caracterizado por uma espécie de fábula, por carregar consigo elementos moralizantes que pretendem dar conta do que o indivíduo pode ou não realizar; das leis (divinas) que ele deve ou não

\footnotetext{
${ }^{1}$ In: Machado de Assis, uma revisão. Rio de Janeiro: Editora In-Folio, 1998.

${ }^{2}$ Deus e Diabo são palavras escritas com letra inicial maiúscula. Nas mais diversas religiões, Deus é assim evocado como forma de respeito por parte daqueles que nele crêem. Já que é colocado como alguém que quer fundar sua religião e se igualar a Deus, o Diabo também tem seu nome assim grafado. Entenderemos melhor a relação entre eles ao longo deste ensaio.
} 
seguir. Além disso, a narrativa é marcada pela ironia - característica presente em vários contos machadianos - e apresenta a história do dia em que o diabo resolveu fundar uma igreja, com o intuito de concorrer com outras religiões.

$\mathrm{O}$ ensaio que aqui apresentaremos pretende analisar o conto procurando explicitar a recorrência do duplo em todas as suas formas de manifestação. Para tanto se faz necessário, em primeiro lugar, tecer algumas importantes considerações acerca do conto enquanto narrativa, da narrativa a ser analisada (o contexto literário em que ela se encontra) e da personagem do Diabo, mostrando o modo como ele se apresenta às pessoas e as metas que procura alcançar.

O conto que nos propomos a analisar, intitulado "A Igreja do Diabo", é dividido em quatro capítulos:

- Capítulo I - De uma idéia mirífica

- Capítulo II - Entre Deus e o Diabo

- Capítulo III - A boa nova aos homens

- Capítulo IV - Franjas e franjas.

O capítulo I conta a história do Diabo através de um velho manuscrito beneditino que narra o dia em que o Diabo teve a idéia de fundar uma igreja, porque se sentia humilhado com o papel avulso que exercia há anos, sem organização, sem regras, sem cânones, sem ritual, sem nada. Com isso, conclui que fundando uma igreja poderia não só combater as outras religiões, como destruí-las. Na passagem abaixo descrita fica bem clara essa idéia:

- Vá, pois, a uma igreja, concluiu ele. Escritura contra Escritura, breviário contra breviário. Terei a minha missa, com vinho e pão à farta, as minhas prédicas, bulas, novenas e todo o demais aparelho eclesiástico. O meu credo será o núcleo universal dos espíritos, a minha igreja uma tenda de Abraão. E depois, enquanto as outras religiões se combatem e se dividem, a minha igreja será única, não acharei diante de mim, nem Maomé, nem Lutero. Há muitos modos de afirmar; há um só de negar tudo [...]. (p.11)

$\mathrm{Na}$ verdade, se pensarmos que toda idéia precisa de um paradigma para se firmar no âmbito social, esta é a grande idéia do diabo: mostrar sua importância através da contrariedade a todas as normas pré-estabelecidas. Além disso, uma igreja como essa, na sua concepção, seria alvo dos muitos 
O Diabo como forma de estabelecimento do duplo: uma análise....

fiéis que têm alguma idéia, por mínima que seja, contrária àquela pregada pelo cristianismo. E o modo que o diabo encontra para realizar seu objetivo é o da negação; ele pensa em criar tudo à imagem e semelhança do catolicismo, mas sob o viés do negar, já que até a negação que fazemos a Deus nada mais é do que uma prova de sua existência.

Após dizer isso o diabo bate as asas rumo ao infinito azul, que é a terra dominada por Deus, seu maior rival. E ele vai ao encontro de Deus, conforme veremos no capítulo II.

Nesse encontro, quando Deus se dirige ao Diabo com "olhos cheios de doçura" e este o chama de "mestre", existem provas demonstrativas da mútua admiração que se traduz na constante troca de elogios das duas partes, como mostra o diálogo apresentado a seguir:

- Sabes o que ele fez? perguntou o senhor, com os olhos cheios de doçura $[\ldots]$

- Tens razão, acudiu o Diabo; mas o amor-próprio gosta de ouvir o aplauso dos mestres. (p. 12)

O Diabo reconhece Deus como seu maior rival; e Deus, por sua vez, também reconhece o Diabo como seu maior inimigo. Na verdade, um é duplo do outro na medida em que, deixando qualquer concepção de crença religiosa em segundo plano, é possível afirmar que todo ser humano é formado a partir desta mistura paradigmática: Deus versus Diabo. É o bem contra o mal que está sempre dentro do indivíduo, como uma luz interna que se acende objetivando mostrar o certo e o errado. Cabe ao homem decidir aquilo que ele quer seguir.

Anjos e arcanjos são inseridos no conto para compor, juntamente com Deus e o Diabo, o cenário celestial:

Deus recolhia um ancião, quando o Diabo chegou ao céu. Os serafins que engrinaldavam o recém-chegado detiveram-se logo, e o Diabo deixou-se estar à entrada com os olhos no senhor [...]. Os serafins, a um sinal divino, encheram o céu com as harmonias de seus cânticos. (p.12-13)

O capítulo II narra, ainda, a chegada do Diabo ao céu. É o momento em que ele decide comunicar a Deus sua intenção de fundar uma igreja e diz ironicamente ao Senhor que precisava comunicá-lo de suas intenções, já que é 
leal e não quer ser acusado de dissimulado. Só esse simples fato já atesta sua dissimulação, visto que tudo foi milimetricamente pensado e calculado. Aqui, a sua idéia de lealdade se perde no momento em que ele transparece toda sua inveja, sua gana em tomar aquilo que o mundo de Deus tem de melhor. Na verdade, ser virtuoso é apenas uma forma mascarada de demonstrar a ganância, característica típica daquele que é o maior inimigo de Deus.

O encontro é marcado por inúmeras provocações ao Deus supremo dos homens, dentre as quais uma merece destaque. Diz o Diabo:

- Só agora concluí uma observação, começada desde alguns séculos, e é que as virtudes, filhas do céu, são em grande número comparáveis às rainhas, cujo manto de veludo rematasse em franjas de algodão. Ora, eu proponho-me a puxá-las por essa franja, e trazê-las todas para minha igreja; atrás delas virão as de seda pura.[...]. (p.13)

Assim, podemos perceber que o texto de Machado se utiliza abertamente da metáfora para a legitimação da retórica entre Deus e o Diabo.

As virtudes são comparadas às rainhas, revestidas por mantos de veludo. $\mathrm{O}$ veludo é representação da doçura, fragilidade e ingenuidade feminina. A partir do momento em que as mulheres possuem virtudes e características tão ligadas à docilidade são presas fáceis para a conquista de fiéis e para a formação de sua igreja e de sua doutrina. Quando aqui se fala em mulher, é preciso deixar claro que se trata de uma mulher específica, semelhante à Eva que foi criada a partir da costela de Adão e, portanto, mesmo sendo rainha, era submissa às leis que eram predominantemente masculinas.

Desse momento em diante a narrativa sela uma discussão entre ambos e, ao final do capítulo, Deus manda o Diabo ir fundar a igreja, chamar todas as virtudes, recolher todos os homens, expulsando-o. E o Diabo vai.

O capítulo III marca o momento em que o Diabo desce à terra e começa a pregação. Argumentando com base em fatores históricos, literários e artísticos, ele defende a inveja, a gula e a preguiça, recebendo diversos adeptos e consolidando sua igreja como a nova igreja hegemônica, que se propaga pelo globo e torna-se conhecida em diversas línguas.

Por fim, o primeiro parágrafo do capítulo IV mostra o triunfo alcançado pelo Diabo na fundação de sua igreja. Entretanto, logo é descrito o momento em que ele percebe as transgressões que seus fiéis vêm cometendo e, conseqüentemente, a diminuição do seu poder, pois a liberdade que deu aos 
O Diabo como forma de estabelecimento do duplo: uma análise....

seus fiéis foi tão grande que o fez perder o controle sobre eles. Isso demonstra que tudo o que o Diabo negou em Deus foi o que na verdade desejava: a capacidade de dominar um povo e o subjugar. Então, vai de novo a Deus que, após escutá-lo, diz:

- Que queres tu, meu pobre Diabo? As capas de algodão têm agora franjas de seda, como as de veludo tiveram de algodão. Que queres tu? É a eterna contradição humana. (p.19)

O Diabo contestava o poder de Deus, a submissão das mulheres a Ele, seus dogmas, tudo o que Ele pré-estabelecia e, na tentativa de arrematar fiéis, promete uma liberdade total que na prática não funciona, uma vez que toda sociedade necessita de normas. Quando o Diabo percebe que essa liberdade não se concretiza, tenta projetar em Deus a culpa de tudo, comprovando as afirmações de que o ser humano é intrinsecamente contraditório e insatisfeito, já que conseguir alcançar um objetivo não é suficiente: ele quer sempre mais e mais.

Para que se percebam todas as questões propostas no início deste ensaio, é necessário que nos questionemos: quem é esse diabo que Machado de Assis aborda com tanta propriedade?

3 O diabo enquanto mito: características e influências no comportamento humano

O mito do Diabo cristão experimentou sua sistematização e unificação por meio dos teólogos dos séculos XII e XIII, adquirindo assim características que foram marcantes, se levarmos em conta o papel que ele possuía em toda a época moderna. Além disso, esse ser do mal teve seu auge na sociedade européia nos séculos XIV, XV e XVI, através dos artistas renascentistas; foi enfrentado pela luz da razão e, conseqüentemente, enfraquecido pelos filósofos e cientistas da época do Iluminismo, nos séculos XVII e XVIII, sendo resgatado pelos poetas e escritores românticos dos séculos XVIII e XIX. E, finalmente, foi apropriado, distorcido e fragmentado pela Indústria Cultural, no século XX.

A partir das produções artísticas do período citado, o mito do Diabo mostrou características de descontinuidade em sua representação, reflexo da visão que a evolução da sociedade européia e ocidental fazia dele. Se em 
dados momentos o Diabo é figura terrível e temida nos afrescos das igrejas e nas telas dos pintores renascentistas, em outros momentos ele é submetido a ironias e aproximado da mentalidade dos burgueses na era romântica, tornando-se reflexo de uma sociedade contrária às ideologias da Idade Média e do antigo regime. E por último, no século XX, o Diabo é encontrado nas telas dos cinemas, nos jogos de videogame, na publicidade, nas letras das músicas de Heavy Metal, na Internet e nas histórias em quadrinhos, evidenciando o desapego ideológico de sua figura e sua banalização enquanto mercadoria para as sociedades de consumo. Figura pouco discutida na Idade Média, limitada a discussão teológica a alguns concílios, aos monastérios e à elite laica cristã, não havia um consenso sobre quem era, ou o que era o Diabo.

A Igreja, preocupada com a influência que o Diabo poderia ter frente aos seus fiéis, e com o intuito de se fortalecer, desenvolveu uma pedagogia do medo, isto é, uma orientação para os dirigentes da Igreja - os sacerdotes - endurecerem o discurso e o controle moral. Aos artistas, por sua vez, era solicitado que criassem obras de arte capazes de exprimir o incrível poder do Maligno e o lamentável destino das almas que no Inferno chegassem. A pedagogia do medo era, nesse sentido, a valoração e o recorrente uso dados às representações da figura do Diabo através das artes plásticas (pintura, escultura, arquitetura), na inculcação, (re)afirmação e (re)construção da mentalidade e do imaginário cristão, voltadas a demonstrar a finitude do corpo físico e a eternidade da alma, temas caros à época. A danação e a salvação eram vistas como próximas, realizando-se na morte. A pedagogia do medo foi a política cultural escolhida pelos governantes para impor sua ideologia e ajudá-los a se perpetuar no poder.

A hegemonia satânica partiu da concepção da própria igreja, pois ela tinha por meta desenvolver uma mentalidade na qual se acreditasse que o mal estava presente no âmago da humanidade e que o Diabo espreitava os homens e aguardava um pequeno deslize de sua fé para que fosse possível corrompêlos. Com essa política cultural (a pedagogia do medo) a igreja esperava captar um maior número de fiéis, uma vez que se colocava como o caminho deles na busca da salvação. Mas, contraditoriamente, as pessoas eram mantidas nas precárias condições sociais que lhes eram destinadas, evitando-se - por meio da repressão moral, da ameaça do juízo final e do medo do inferno - as insubordinações e revoltas.

Os medos escatológicos contribuíram, portanto, para que o período 
O Diabo como forma de estabelecimento do duplo: uma análise....

entre os séculos XIV e XVI fosse marcado pela efervescência do imaginário sobre o Diabo, como podemos notar pela quantidade de obras de arte que ilustram essa angústia sofrida pelos europeus. Machado de Assis faz uso desse medo para criar uma personagem que mostra um "inferno" completamente diferente. O "Diabo" criado por ele, como veremos na seqüência, em nenhum momento é pior que Deus, uma vez que se mostra capaz de realizar as mesmas coisas que Deus realiza; mostra-se capaz de organizar dogmas e conduzir uma legião de fiéis, entretanto, de forma bem mais liberal e sem hipocrisias.

Em um universo cada vez mais marcado pelo hedonismo, ou seja, pela promoção do indivíduo e pela busca da felicidade ou, mesmo, de um prazer incessantemente renovado, o Diabo é muitas vezes consumido como algo positivo. Não só deixou de existir como figura exterior aterrorizante, como nem sequer provoca mais medo de si mesmo, o temor do demônio interno, aquele mesmo dos psicanalistas.

Sylvie Dion, em seu estudo científico sobre o diabo, afirma que ele é provavelmente a personagem mais importante dos seres fantásticos que povoam o universo da literatura oral. O diabo das pessoas simples é, entretanto, bem diferente da figura literária ou teológica: ele é uma personagem incômoda e familiar, temida em razão da sua capacidade nociva, do mal que introduz nas pequenas coisas da vida quotidiana.

Segundo Mircéa Eliade (1965, p. 83), "quanto mais o homem é religioso, mais ele dispõe de modelos exemplares para seus comportamentos e suas ações". Veremos que esses modelos, no contexto do conto que escolhemos trabalhar, virão não só do Diabo, mas também de Deus, que se porta de forma tão irônica e sarcástica quanto seu grande rival. Essa sagacidade será, ao fim, transmitida na forma de moral - Deus, ao perceber a derrota do Diabo, vangloria-se com o acontecido e mostra-se como um ser vingativo bem diferente do que se espera do Criador, que é perfeito.

Por outro lado, no que tange à ironia citada por Eliade, Flavio Aguiar comenta, no inicio dos seus Contos:

Mas a ironia maior de Machado é nos incluir neste seu mundo de profundas convulsões interiores que aparecem timidamente na calma superfície que, convencionalmente, nos parece ser a vida. Os silêncios são terríveis: as histórias escondem um segredo qualquer, uma palavra ou gesto que é impossível precisar qual seja, mas que sabemos, quebraria o encanto, espatifaria o espelho das convenções e poria os personagens 
ao lado de sua própria realidade. Talvez seja a "lição" (ou sentido) mais contundente de Machado, o silêncio que há no meio das falsidades, das frases vazias e sonorosas, desse mundo oco e inautêntico de escravidão e pancadas onde vivem seus personagens.

No fundo da calma superfície de despreocupação aparente, esconde-se a aguilhão de uma lucidez desesperada. (AGUIAR, 1976, p.8).

\section{Deus e o diabo: conclusões possíveis na perspectiva do conto}

Analisando Deus e o Diabo no âmbito da narrativa, vimos que graças à liberdade de sua igreja, o Diabo possui grande facilidade de pregação de uma doutrina subversiva que abriga milhares de fiéis (ou infiéis, dependendo do sentido dado ao termo "fiel", visto que esta fidelidade está intimamente ligada à escolha de conduta de cada um). Todavia, no momento em que tudo é permitido e a prática da bondade é proibida, os homens procuram novamente $\mathrm{o}$ caminho da virtude e passam a seguir os doutrinamentos emanados por Deus. A metáfora que Deus utiliza para explicar a situação ao diabo é aqui entendida como a síntese dessa essência contraditória do ser humano. O Diabo vê os homens como seres de vontade hipócrita, uma vez que possuem uma natureza má e pecaminosa e procuram ocultar isso. Quando têm a chance de abandonar os ensinamentos divinos, não conseguem e, assim, mostram-se dicotômicos, duais e possuidores de uma essência que oscila entre vícios e virtudes que fazem parte do seu caráter dúbio. E é justamente nesse ponto que encontramos a recorrência do duplo: o homem é marcado por vícios e virtudes, Deus e o Diabo são marcados por vícios e virtudes que se misturam na formação do ser humano. Na realidade, eles são um só e exercem, no conto, a função de representação da alma humana, da essência do ser humano.

Contudo, se analisarmos a retomada da idéia de organização de seu reino, desejada pelo Diabo, percebemos as alusões feitas por ele à Igreja Divina. O Diabo queria ter sua própria missa com vinho, pão, o que remete ao jejum cristão e à celebração do corpo e sangue de Cristo. Ele faz referências bíblicas como a da "tenda de Abraão" e, numa espécie de aspiração de reunião dos povos divididos pelas outras religiões, busca a religião única e suprema, que terá uma unidade fiel e verdadeira. Através das figuras de Maomé e Lutero percebemos, ao invés de uma ameaça advinda da religião islâmica, a presença de um obstáculo de fácil transposição, talvez porque para ele não existem obstáculos, apenas sua forte vontade. 
O Diabo como forma de estabelecimento do duplo: uma análise....

A descrição feita por Machado ao Diabo atribui ao mesmo uma imagem imponente, definindo-o como "magnífico e varonil", além de caracterizá-lo como alguém que possui uma suntuosidade superior à divina. Isso fica claro pelo fato de que o Diabo não apenas conversa com Deus sobre seus planos, mas também o desafia. Percebemos uma alusão ao episódio bíblico de expulsão de Lúcifer (o anjo da luz) dos céus, através do ódio e da ânsia de vingança do Diabo. Ao chegar aos céus, o Diabo não entra. A iniciação de seu recurso retórico acontece na entrada, após ser questionado por Deus sobre por que o velho ancião foi mandado para lá, e responder ironicamente que não sabe, aproveitando para expor suas idéias. O céu é referido pelo Diabo como uma hospedaria de preço alto e a imagem divina é comparada com a de um negociador. A ironia vem como recurso de transferência de sua veia sarcástica à do autor. Diante do discurso do Diabo, comparando pessoas de boa índole a mantos de veludo e os bons atos a franjas de seda, o Senhor mostra dissimulação ao murmurar que se trata de pensamentos de um "velho retórico". O sorriso triunfante do Diabo dá espaço ao murmúrio divino, num forte indício dos papéis inversos.

Para Jung, a existência do Diabo é indubitável, na medida em que se trata de um mito eficaz, de um arquétipo, ou seja, de uma estrutura da consciência individual. Do mesmo modo que Deus representa o lado claro dessa consciência, o Diabo representa o seu lado sombrio e escuro. Na sua obra Modern man in a search of a soul (1933), Jung declara que Deus e o Diabo são as duas faces de uma mesma moeda. Os arquétipos, com efeito, não são metáforas, mas imagens pulsionais indutoras de comportamentos. Desse ponto de vista, o mito do Diabo é verdadeiro. Em todas as civilizações, o Diabo, seja ele representado iconograficamente como serpente ou como dragão, concentra em si as reações de medo, de revolta, de rejeição, assim como o fascínio por todas as delícias proibidas. No momento em que Deus se revolta com a chegada do Diabo ao céu e se vangloria com o seu fracasso, percebemos nele esse lado maligno, competitivo, equiparando-se ao Diabo.

Nesse sentido, tomando por base o conto, podemos afirmar que Deus e o Diabo constituem o reflexo do próprio homem. Satanás significa liberdade, progresso, ciência, vida. Identificar-se com o demônio nada mais é do que reconhecer-se como um ser de múltiplas personalidades; alguém que não é totalmente bom, nem totalmente ruim e que pode, em algum momento de sua existência, refletir no semblante o olhar, o riso, a zombaria impressa nas feições tradicionais do Diabo. O Diabo passa a expressar a rebelião contra a fé 
e a moral tradicional, representando a revolta do homem, mas com a aceitação do sofrimento, porque este é uma fonte purificadora do espírito, uma nobreza moral da qual só pode surgir o bem da humanidade. E o demoníaco torna-se o símbolo do Romantismo: demoníaco como paixão, como terror do desconhecido, como descoberta do lado irracional existente no homem - a explosão da imaginação contra obstáculos excessivos da consciência e das leis.

Por fim, Bosi (2000, p.86) diz que:

Chegando mais perto dos textos vê-se que a vida em sociedade, segunda natureza do corpo, na medida em que exige máscaras, vira também irreversivelmente máscara universal. A sua lei, não podendo ser a da verdade subjetiva recalcada, será a da máscara comum exposta e generalizada. O triunfo do signo público. Dá-se a coroa à forma convencionada, cobrem-se de louros as cabeças bem penteadas pela moda. Todas as vibrações interiores calam-se, degradam-se à veleidade ou rearmonizam-se para entrar em acorde com a convenção soberana. Fora dessa adequação só há tolice, imprudência ou loucura.

A partir disso, podemos dizer que essa relação Deus - Diabo, presente no conto machadiano, nada mais é do que uma forma de manifestação das máscaras universais presentes na sociedade. Os papéis inversos assumidos por cada personagem, e explicitados na narrativa, são a comprovação do duplo existente; Deus é sósia do Diabo, e o Diabo é sósia de Deus. Eles manifestam um comportamento público natural e, mais do que isso, presente no ser humano, que é essencialmente contraditório, insatisfeito com si próprio, que busca no outro a conquista de sua felicidade; que é ele e, concomitantemente, o outro; é Deus e, ao mesmo tempo, o Diabo. Todos têm dentro de si um pouco de cada um, criando-se assim a forma completa do "ser" humano. Ambos querem triunfar e querem ser reconhecidos: o Diabo quer ser Deus, ter uma igreja, com vinho, cálice e fiéis; e Deus quer ser triunfante - através da lição de moral dada no último capítulo do conto, quer mostrar quem manda, ou seja, quem tem o domínio da situação. E essa atitude não é em nada absurda; muito pelo contrário, é característica dos contos machadianos, dos contosteorias que traduzem a amargura de quem observa a força de uma necessidade objetiva que une a alma mutável e débil de cada homem ao corpo uno, sólido e ostensivo da Instituição. 


\section{Referências}

AGUIAR, F. Murmúrios no espelho. In: ASSIS, Machado de. Contos. São Paulo: Ática, 1976.

CHALHOUB, S.; PEREIRA, L. A. de M.(Org). A História do Brasil em papéis avulsos de Machado de Assis. In: Coleção Histórias do Brasil. A História Contada. Rio de Janeiro: Nova Fronteira,1998.

FISCHER, L. A. Contos de Machado: da ética à estética. In: Machado de Assis, uma revisão. Rio de Janeiro: In-Folio, 1998.

GLEDSON, J. Contos: uma antologia Machado de Assis. São Paulo: Companhia das Letras, 2004.

GOMES, E. Espelho contra espelho: estudos e ensaios. São Paulo: Instituto Progresso Editorial S.A, (s.d.).

GOTLIB, N. B. Teoria do conto. 2. ed. São Paulo: Ática, 1985.

MATIAS, F. dos S. Intertextualidade: a presença da obra Fausto de Goethe no conto "A igreja do Diabo"de Machado de Assis. MAFUÁ Revista de Literatura em Meio Digital ano 5, n.8, 2007.

SILVA, M. O. A igreja do diabo: (des)ordem rabelasiana. Disponível em: $<$ http://vbookstore. uol.com.br/ensaios/igreja_do_diabo.shtml>.

Recebido para publicação em 17 de agosto de 2008. Aceito para publicação em 28 de outubro de 2008. 